\title{
Constraints to restoring fire and grazing ecological processes to optimize grassland vegetation structural diversity
}

\author{
Authors: John D. Scasta, Courtney Duchardt, David \\ M. Engle, James R. Miller, Diane M. Debinski, Ryan \\ N. Harr
}

NOTICE: this is the author's version of a work that was accepted for publication in Ecological Engineering. Changes resulting from the publishing process, such as peer review, editing, corrections, structural formatting, and other quality control mechanisms may not be reflected in this document. Changes may have been made to this work since it was submitted for publication. A definitive version was subsequently published in Ecological Engineering, 95, October 2016 DOI\#10.1016/i.ecoleng.2016.06.096

Scasta, John D., Duchardt, Courtney, Engle, David M., Miller, James R., Debinski, Diane M., \& Harr, Ryan N. (2016). Constraints to restoring fire and grazing ecological processes to optimize grassland vegetation structural diversity. Ecological Engineering, 95, 865-875. doi:10.1016/ j.ecoleng.2016.06.096

Made available through Montana State University's $\underline{\text { ScholarWorks }}$ scholarworks. montana.edu 


\title{
Constraints to restoring fire and grazing ecological processes to optimize grassland vegetation structural diversity
}

\author{
John Derek Scasta ${ }^{\mathrm{a}, *}$, Courtney Duchardt ${ }^{\mathrm{a}, \mathrm{b}}$, David M. Engle ${ }^{\mathrm{c}}$, James R. Miller ${ }^{\mathrm{b}}$, \\ Diane M. Debinski ${ }^{\mathrm{d}}$, Ryan N. Harr ${ }^{\mathrm{e}}$ \\ a Department of Ecosystem Science and Management, University of Wyoming, Laramie, WY, USA \\ ${ }^{b}$ Department of Natural Resources and Environmental Sciences, University of Illinois, Urbana, IL, USA \\ ${ }^{c}$ Department of Natural Resource Ecology and Management, Oklahoma State University, Stillwater, OK, USA \\ ${ }^{\mathrm{d}}$ Department of Ecology and Evolutionary Biology Department, Iowa State University, Ames, IA, USA \\ e Iowa Department of Natural Resources, Des Moines, IA, USA
}

\begin{abstract}
A B S T R A C T
Extirpation of the ecosystem engineer (bison) and its interaction with fire, coupled with the utilitarian concept of moderate grazing, have contributed to homogenization of grassland habitat in North America. Although cattle may serve as a proxy for bison, combining fire with cattle grazing has been uncommon and to date managers have not always successfully applied cattle and controlled burns as tools to manipulate grassland vegetation heterogeneity and increase habitat diversity. Using an information-theoretic approach, we assessed factors constraining the fire-grazing interaction ecological process to engineer habitat structure of grasslands via patch-burn grazing. We assessed how grazing, fire, and biotic and abiotic features in tallgrass prairie influenced establishment and maintenance of low vegetative structure in burned patches, the positive feedback driving the fire-grazing interaction, and subsequent structural heterogeneity across a pasture. Four pastures were divided into three patches with a different patch burned annually in March/April from 2007 to 2013. Cattle were stocked from light to heavy (1.1-4.4 AUM/ha) from May to October ( $\sim 150$ days) with access to the entire pasture. We hypothesized that the exotic C3 grass tall fescue (Schedonorus arundinaceus), lag-time between burning date and the date cattle were put into experimental pastures, and burn date would be the constraining factors. However, the most informative model included stocking rate, date of burn completion, and precipitation. The lightest cattle stocking rate did not establish low vegetative structure in the burn patch, which resulted in the lowest heterogeneity among patches. The heaviest cattle stocking rate established but did not maintain low vegetative structure in the burn patch. The intermediate cattle stocking rate maintained the lowest vegetative structure in the burn patch and the greatest heterogeneity among patches, i.e., the best efficacy of patch-burn grazing to engineer habitat structural heterogeneity. The relationships of stocking rate to burn patch vegetative structure and to landscape heterogeneity were both quadratic and were both optimized at intermediate stocking rate.
\end{abstract}

\section{Introduction}

In North American grasslands, extirpation of the facilitating ecosystem engineer (bison) and its interaction with frequent fire, coupled with the utilitarian concept of moderate grazing, have contributed to homogenization of grassland habitat. Because the utilitarian concept of moderate grazing seeks to eliminate the

\footnotetext{
* Corresponding author at: Department of Ecosystem Science and Management, University of Wyoming, Agriculture C 2004, Laramie, WY 82071, USA

E-mail address: jscasta@uwyo.edu (J.D. Scasta).
}

extreme ends of the grazing utilization gradient and evenly distribute utilization across the landscape, homogeneous vegetation structure is the result (Fuhlendorf et al., 2012). This homogenization has been linked with severe declines in grassland bird populations, as the structural habitat requirements of these species are often diverse (Brennan and Kuvlesky Jr., 2005; Fuhlendorf et al., 2006; Machicote et al., 2004). Examples of bird species in decline due to habitat homogenization include Henslow's sparrows (Ammodramus henslowii) that need high vegetation structure, mountain plovers (Charadrius montanus) that need low vegetation structure, and lesser prairie chickens (Tympanuchus pallidicinctus) 
Table 1

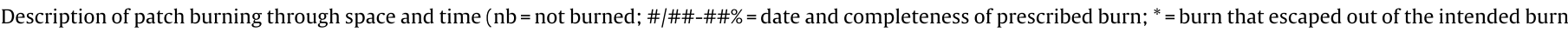
patch and burned remainder of pasture) with experimental pastures in the Grand River Grasslands of Iowa, USA, 2007-2013.

\begin{tabular}{|c|c|c|c|c|c|c|c|}
\hline \multirow{2}{*}{$\begin{array}{l}\text { Pasture } \\
\text { Patch }\end{array}$} & \multicolumn{7}{|c|}{ Year } \\
\hline & 2007 & 2008 & 2009 & 2010 & 2011 & 2012 & 2013 \\
\hline \multicolumn{8}{|c|}{ Kellerton North } \\
\hline Patch 1 & $3 / 19-60 \%$ & $\mathrm{nb}$ & $\mathrm{nb}$ & $4 / 10-40 \%$ & $\mathrm{nb}$ & $\mathrm{nb}$ & $3 / 19-95 \%$ \\
\hline Patch 2 & $\mathrm{nb}$ & $3 / 29-83 \%$ & $\mathrm{nb}$ & nb & $3 / 18-95 \%$ & nb & $\mathrm{nb}$ \\
\hline Patch 3 & $\mathrm{nb}$ & $\mathrm{nb}$ & $3 / 6-55 \%$ & $\mathrm{nb}$ & $\mathrm{nb}$ & $3 / 12-95 \%$ & $\mathrm{nb}$ \\
\hline \multicolumn{8}{|c|}{ Pyland North } \\
\hline Patch 1 & $3 / 28-70 \%$ & nb & $\mathrm{nb}$ & $4 / 9-80 \%$ & $\mathrm{nb}$ & $\mathrm{nb}$ & $4 / 3-95 \%$ \\
\hline Patch 2 & $\mathrm{nb}$ & $3 / 12-85 \%$ & $\mathrm{nb}$ & nb & $3 / 16-93 \%$ & $\mathrm{nb}$ & nb \\
\hline Patch 3 & $\mathrm{nb}$ & $\mathrm{nb}$ & $4 / 22-70 \%$ & $\mathrm{nb}$ & $\mathrm{nb}$ & $3 / 9-100 \%$ & $\mathrm{nb}$ \\
\hline \multicolumn{8}{|c|}{ Pyland South } \\
\hline Patch 1 & $3 / 28-85 \%$ & $\mathrm{nb}$ & *3/17-85\% & $4 / 9-78 \%$ & $\mathrm{nb}$ & $\mathrm{nb}$ & $4 / 3-100 \%$ \\
\hline Patch 2 & $\mathrm{nb}$ & $3 / 12-95 \%$ & $* 3 / 17-85 \%$ & nb & $3 / 16-100 \%$ & $\mathrm{nb}$ & $\mathrm{nb}$ \\
\hline Patch 3 & $\mathrm{nb}$ & $\mathrm{nb}$ & $3 / 17-85 \%$ & $\mathrm{nb}$ & $\mathrm{nb}$ & $3 / 9-100 \%$ & $\mathrm{nb}$ \\
\hline \multicolumn{8}{|c|}{ Ringgold South } \\
\hline Patch 1 & $3 / 29-33 \%$ & $\mathrm{n}$ & $\mathrm{nb}$ & $4 / 10-40 \%$ & $\mathrm{nb}$ & $\mathrm{nb}$ & $4 / 4-99 \%$ \\
\hline Patch 2 & $\mathrm{nb}$ & $3 / 29-73 \%$ & $\mathrm{nb}$ & $\mathrm{nb}$ & $3 / 18-90 \%$ & $\mathrm{nb}$ & nb \\
\hline Patch 3 & $\mathrm{nb}$ & $\mathrm{nb}$ & $3 / 17-85 \%$ & $\mathrm{nb}$ & $\mathrm{nb}$ & $3 / 15-95 \%$ & $\mathrm{nb}$ \\
\hline
\end{tabular}

that require both high and low vegetation structure (Derner et al., 2009; Hovick et al., 2015).

Altering cattle grazing distribution by moving feeding locations, redistributing water, or burning spatially discrete fires has been proposed as a proxy for bison and wildfire as grassland habitat engineers (Derner et al., 2009). However, conventional cattle grazing, in and of itself, is not a replication of how bison and fires engineered habitat and managers need specifications for how to mechanistically alter the cattle-forage interaction to achieve habitat engineering objectives. Conventional cattle grazing is different than historic bison grazing because bison selection and distribution patterns were driven by frequent and low-intensity fires, but the restoration of the fire regime could similarly alter cattle herbivory (Allred et al., 2011a,b). While we know that altering feeding locations or water distribution to focus cattle in a specific area are effective tools for manipulating grazing behavior, these practices cannot replicate the effects that strategically applied fires and the response of bison have on vegetation structure (Machicote et al., 2004; Towne et al., 2005). Only prescribed fire maintains herbaceous plant composition by reducing woody plant encroachment in grasslands while also accomplishing grazing manipulation (Anderson, 2006). Furthermore, the ecological engineering principle of 'imitation' is conventionally applied by spatially and temporally variable fires and the response of grazing animals - imitating the developmental processes regulating grasslands and modifying grassland habitat prior to European settlement of North America (Fuhlendorf et al., 2009; Jones et al., 1996; Jǿrgensen and Nielsen, 1996; Kangas, 2004; Levin, 1992; Lü et al., 2011; Turner, 1989).

The historic interaction between fire and grazing has been mimicked contemporarily by the management practice of patch-burn grazing or burning discrete patches within pastures and allowing cattle to select where they graze. This application of patch-burn grazing was conceived as a restoration framework of recoupling grazing and fire interactions as an ecological process that maintained grassland flora and fauna in North America (Fuhlendorf and Engle, 2001; Fuhlendorf and Engle, 2004). Although patch-burn grazing experiments have been effective in establishing habitat structural heterogeneity in some experiments, they have not always altered vegetation structure in a predictable way, and specifications are lacking to guide effective applications of this ecological engineering concept (Derner et al., 2009; McGranahan et al., 2012b). The utility and transferability of successful projects also are limited because the majority of studies have been conducted on conservation land consisting of large contiguous pastures of undisturbed warm-season grasses (Fuhlendorf and Engle, 2004; Leis et al., 2013; Vermeire et al., 2004).

In reality, most grazed grasslands are highly fragmented, have a long history of overgrazing, and a high component of invasive species such as cool-season grasses (Brennan and Kuvlesky Jr., 2005; McGranahan et al., 2012b; Quan et al., 2015). From a social perspective, continuing agricultural production on these working lands also complicates restoration of grassland habitat. Ranchers rely on income from cattle, so stocking rates must often be maintained at a certain minimum level. However, how stocking rate affects patch-burn grazing is still not well understood, so we are faced with a knowledge gap that severely limits effective application (Fuhlendorf and Engle, 2004; Helzer and Steuter, 2005). Application of patch-burn grazing often has lacked the quantitative rigor and precision that is characteristic of engineering approaches to solving problems (Kangas, 2004), and this lack of control is especially relevant where applications have failed to meet predetermined objectives of establishing a mosaic of habitat structure (McGranahan et al., 2012b).

Developing and refining patch-burn grazing management specifications to effectively employ cattle as ecosystem engineers will benefit agriculture, conservation, and restoration ecology (Derner et al., 2009; Fuhlendorf and Engle, 2004; McGranahan et al., 2012b). This is especially crucial in systems where the utility of patchburning is still not established - namely, smaller grassland patches located within a matrix with a high proportion of wooded or agricultural lands and is an issue identified as a severe knowledge gap (Miller et al., 2012). Because efficacy of patch-burn grazing has produced mixed results in these types of systems (McGranahan et al., 2012b) and to refine patch-burn grazing project specifications, we examined factors potentially constraining the efficacy of patch-burn grazing on sites within such a matrix. Using an information-theoretic approach, we modeled potential constraints to the primary positive feedback, which is here considered to be the focal grazing in the burn patch that establishes and maintains low vegetative structure (Allred et al., 2011a; Archibald et al., 2005). We also assessed how the establishment of the primary positive feedback influences structural heterogeneity of vegetation within a pasture and the ability to successfully conduct prescribed fire operations. This relationship between heterogeneity and successful burning is a function of the negative feedback, or establishment of unburned areas not as likely to be grazed due to accumulated dormant plant material deterring grazing and increasing burn potential following Fuhlendorf and Engle (2004). Our objectives for this study were to: (1) determine constraints limiting establish- 
Table 2

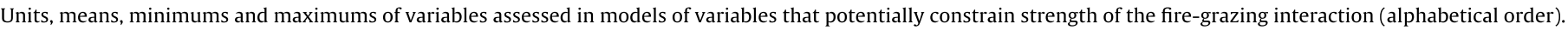

\begin{tabular}{|c|c|c|c|c|}
\hline Variable & Unit & Mean & Minimum & Maximum \\
\hline Bare ground & Percent & 19 & $<1$ & 49 \\
\hline Burn completeness & Percent & 81 & 33 & 100 \\
\hline Burn date & Numerical day & $83(3 / 24)$ & $65(3 / 6)$ & $112(4 / 22)$ \\
\hline Lag-time & Days after fire & 41 & 15 & 66 \\
\hline Litter cover & Percent & 16 & 1 & 39 \\
\hline Seasonal precipitation & Millimeters & 500 & 450 & 780 \\
\hline Slope difference & Meters & 24 & 12 & 33 \\
\hline Stocking date & Numerical day & $124(5 / 4)$ & $106(4 / 16)$ & $140(5 / 20)$ \\
\hline Stocking rate & AUM per ha & 2.47 & 1.08 & 4.44 \\
\hline Tall fescue cover & Percent & 33 & 13 & 59 \\
\hline Warm-season grass cover & Percent & 16 & 4 & 37 \\
\hline
\end{tabular}

Table 3

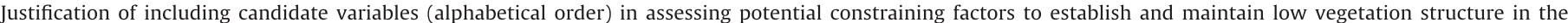
burn-patch in patch-burn grazed pastures. The study location is the Grand River Grasslands of Iowa, USA from 2007 to 2013.

\begin{tabular}{|c|c|}
\hline Candidate variables & Justification for inclusion $^{a}$ \\
\hline Bare ground & indicator of fuel discontinuity and incompleteness of burn (9) \\
\hline Burn completeness & inhibited by vegetation patterns $(4,10-12)$ \\
\hline Burn date & inhibited by live-fuel moisture (10-12) \\
\hline Lag-time & influential parameter for herbage utilization $(1,8)$ \\
\hline Litter cover & increases fire potential and reduces herbivory $(6)$ \\
\hline Seasonal precipitation & temporal variation relative to critical growth periods could impede grazing effects (5) \\
\hline Slope difference & constrains herbivore distribution $(1,2)$ \\
\hline Stocking date & forage quality declines quadratically after fire (1) \\
\hline Stocking rate & key grazing management decision $(3,7)$ \\
\hline Tall fescue cover ${ }^{\mathrm{b}}$ & reduces fire spread and herbivory $(10-12)$ \\
\hline Warm-season grass cover & important for fire success and herbivory (11) \\
\hline
\end{tabular}

a Numbers refer to the literature source justifying inclusion of a specific variable (1 - Allred et al. (2011a,b); 2 - Bailey et al. (1996); 3 - Briske et al. (2011); 4 - Davies

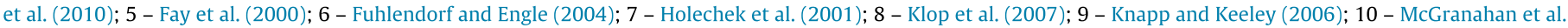
(2012a); 11 - McGranahan et al. (2012b); 12 - McGranahan et al. (2013)).

b Schedonorus arundinaceus.

ment of low vegetative structure in the most recently burned patch, the positive feedback, (2) understand if constraints were biotic, abiotic, grazing management, fire management or some related combination, (3) use model selection results to demonstrate how those constraints influence heterogeneity, and (4) develop recommendations for implementing patch-burn grazing as an ecological engineering approach to habitat restoration in highly altered grasslands.

\section{Methods}

\subsection{Study area and design}

This experiment was initiated in the Grand River Grasslands of southern Iowa, and northern Missouri (USA) to examine the effects of the fire-grazing interaction compared with more traditional forms of land management (Table 1). All study sites were located within ecoregion 40 Central Irregular Plains and sub-ecoregion 40a Loess Flats and Till Plains which are characterized by gently undulating hills with naturally fertile and dark loess soils over glacial till (Chapman et al., 2002). Pastures are co-dominated by native tallgrass prairie species (perennial $\mathrm{C} 4$ graminoids such as big bluestem (Andropogon gerardii) and exotic C3 graminoids and legumes (such as tall fasecue (Schedonorus arundinacea), smooth brome (Bromus inermis), birdsfoot trefoil (Lotus corniculatus), and clovers (Trifolium spp.)) with native shrubs present (Scasta et al., 2014). The Grand River Grasslands has been identified as one of the most promising areas in the region to restore a functioning tallgrass prairie ecosystem (Davit, 2008). Study pastures ranged from 23 to 32 ha $(\bar{x}=28$ ha $)$ with seasonal grazing of domestic cattle.

Each of four pastures was confined with a perimeter fence with no internal fencing and divided into three patches with fire breaks that were mowed prior to burning. Within each pasture, a different patch was burned each year over a seven-year period (2007-2013). Thus, each patch in each pasture was burned at least twice during the course of the study (Table 1). Patches were burned in the dormant season from mid-March to early-April as snow melt allowed. Cattle were mature Angus cows stocked seasonally from May to October ( $\sim 150$ days) with access to the entire pasture at stocking rates ranging from light to heavy (1.08-4.44 AUM/ha). Detailed study area map and aerial image of a treatment pasture and burn patches are available in Appendix A in Supplementary material.

\subsection{Data collection}

Vegetative structure in all patches was measured in mid-July from 2007 to 2013 using a non-destructive method of visual obstruction. Visual obstruction by vegetation is considered to be the three-dimensional capacity of herbaceous plant biomass to obstruct the visibility of an organism and was originally designed to assess how grassland birds perceived vegetation structure (Robel et al., 1970). The Robel pole method of measuring visual obstruction documents the bands of a pole with clear demarcations for the point at which the lowest band is no longer visible and has been found to have a high correlation with vegetation biomass (Robel et al., 1970; Vermeire and Gillen, 2001). We used PVC poles delineated at $0.1 \mathrm{~m}$ intervals observed from $4 \mathrm{~m}$ distance and $1 \mathrm{~m}$ height from each of the cardinal directions (Robel et al., 1970; Vermeire and Gillen, 2001). Post-grazing forage residue was sampled in the fall by measuring vegetation visual obstruction at 10 points in each patch, 30 total points per pasture, on transects oriented on the long axis of each pasture. Visual obstruction was calibrated with herbage mass clipped in $10,0.1 \mathrm{~m}^{2}$ quadrats (Vermeire and Gillen, 2001). Post-grazing forage residue served as the basis for adjusting stocking rate to attain the goal of low forage mass, and therefore, low visual obstruction in the burn patch. 
Table 4

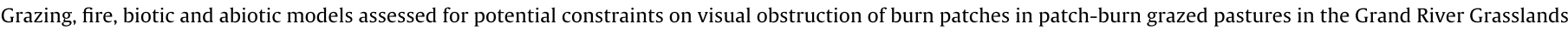
of Iowa, USA from 2007 to 2013 . Year is a random effect in all model results.

\begin{tabular}{|c|c|c|c|c|}
\hline Model & $\mathrm{K}^{\mathrm{a}}$ & $\mathrm{AICC}^{\mathrm{b}}$ & $\triangle \mathrm{AICc}$ & $\omega_{\mathrm{i}}^{\mathrm{c}}$ \\
\hline \multicolumn{5}{|l|}{ Grazing management models } \\
\hline Stocking rate (stck_rate) & 2 & 81.00 & 0.00 & 0.98 \\
\hline Stocking date & 2 & 89.99 & 8.99 & 0.01 \\
\hline Lag-time between fire and grazing & 2 & 91.49 & 10.49 & $<0.01$ \\
\hline All grazing covariates & 4 & 92.06 & 11.06 & $<0.01$ \\
\hline \multicolumn{5}{|l|}{ Fire models } \\
\hline Burn completeness (burn_com) & 2 & 78.82 & 0.00 & 0.94 \\
\hline Burn date & 2 & 91.09 & 12.27 & $<0.01$ \\
\hline All fire covariates & 3 & 84.42 & 5.60 & 0.06 \\
\hline \multicolumn{5}{|l|}{ Biotic models } \\
\hline Litter (litt) & 2 & 84.12 & 0.00 & 0.91 \\
\hline Warm-season grass & 2 & 89.74 & 5.62 & 0.06 \\
\hline Tall fescue (S. arundinaceus) & 2 & 91.00 & 6.88 & 0.03 \\
\hline All biotic covariates & 4 & 95.34 & 11.22 & $<0.01$ \\
\hline \multicolumn{5}{|l|}{ Abiotic models } \\
\hline Precipitation (precp) & 2 & 80.66 & 0.00 & 0.83 \\
\hline Bare ground & 2 & 83.86 & 2.97 & 0.17 \\
\hline Slope & 2 & 99.36 & 18.70 & $<0.01$ \\
\hline All abiotic variables & 4 & 94.69 & 14.03 & $<0.01$ \\
\hline \multicolumn{5}{|l|}{ Best models $^{\mathrm{d}}$} \\
\hline burn_com + stck_rate + precp + litt & 5 & 67.23 & 0.00 & 0.57 \\
\hline burn_com + stck_rate + precp & 4 & 68.27 & 1.04 & 0.34 \\
\hline Null (intercept with year as random) & 1 & 84.60 & 17.37 & $<0.01$ \\
\hline Global model with all covariates & 12 & 99.73 & 32.50 & $<0.01$ \\
\hline
\end{tabular}

a Number of parameters in the model.

b Akaike's information criterion corrected for small sample sizes. Values are based on differences from the best model within each stage.

c Model weight.

d The next best model had a $\triangle \mathrm{AICC}>6$ and all other models had $\omega_{\mathrm{i}} \leq 0.02$ and are not presented in this table.

At the same time vegetative structure was measured, the abundance of warm-season grass, litter, bare ground, and tall fescue were sampled by estimating canopy cover of $0.5 \mathrm{~m}^{2}$ quadrats at each point vegetation structure was measured using the following cover classes: $0,<1 \%, 1-5 \%, 6-25 \%, 51-75 \%, 76-95 \%$ and $96-100 \%$ respectively categorized as $0,1,3,16,38,63,86$, and 98 (Daubenmire, 1959). Canopy cover total was allowed to exceed $100 \%$ to account for overlapping vegetation layers. Measurements were taken along permanent line transects positioned perpendicular to the long axis of each patch with equally spaced observation points positioned $25 \mathrm{~m}$ on both sides of the line. Each patch had two transects, except one that had three due to irregular shape and orientation, with 30 total observation points per patch assessed annually in mid-July. We calculated the average slope difference of each pasture using a 1-m resolution digital elevation model (DEM) of Ringgold County, Iowa, (Iowa NRGIS, 2013) and calculating slope using the Spatial Analyst function in ArcGIS 10 (ESRI, 2011). Precipitation data were acquired from the Mt. Ayr, IA, USA Mesonet station (Iowa Environmental Mesonet, 2014). Because the desired patch contrast was not attained during the early years of this study, stocking rate was manipulated in three phases of the project to ascertain the rate at which heterogeneity between patches was optimized. Stocking rate was heaviest ( $3.2 \pm 0.2 \mathrm{AUM} / \mathrm{ha})$ in Phase

\section{Table 5}

Top candidate model coefficient estimates, standard error and 95\% confidence intervals $(\mathrm{CI})$ for potential constraints of vegetation visual obstruction within burn patches established by the fire-grazing interaction in the Grand River Grasslands of Iowa, USA, 2007-2013.

\begin{tabular}{llll}
\hline Parameter & Estimate & SE & $95 \%$ CI \\
\hline Intercept & 711.33 & 207.56 & 280.88 to 1141.78 \\
Stocking rate & 2.49 & 1.20 & 0.10 to 4.87 \\
Burn completeness & -3.40 & 1.55 & -6.61 to -0.18 \\
Litter & 0.42 & 0.42 & -0.45 to 1.28 \\
Precipitation & -5.31 & 2.54 & -10.57 to -0.05 \\
\hline
\end{tabular}

1 (2007-2009) due to pre-existing contracts between public land managers and landowners. No vegetative production data were available for the study sites during this initial phase. In Phase 2 (2010-2011), stocking rate was reduced to the lightest levels in the study $(1.5 \pm 0.1 \mathrm{AUM} / \mathrm{ha})$. To address the issue of no vegetative production data we began sampling post-grazing forage residue (described above) to guide stocking rate decisions in 2011 through 2013 (which included the wettest and driest years during the course of the study). In Phase 3 (2012-2013), stocking rate was adjusted to a more moderate level $(2.4 \pm 0.2 \mathrm{AUM} / \mathrm{ha})$. Our results following these stocking rate adjustments are informative because other researchers have identified grazing management decisions as a knowledge gap in fire-grazing based heterogeneity management (Fuhlendorf and Engle, 2004; Helzer and Steuter, 2005).

\subsection{Constraining variables}

We identified variables as potential constraints of the firegrazing interaction a priori based on our observations of the fire-grazing interaction and on peer-reviewed literature. Descriptions of variables and justification for variable selection are summarized in Tables 2 and 3, respectively. Grazing management was quantified with three variables: stocking rate, stocking date, and lag-time. Stocking rate has been proposed as the key grazing management decision that is more important than type of grazing system (Briske et al., 2011; Holechek et al., 2001). Stocking date might influence the strength of the interaction between grazing and plant phenology because forage quality declines quadratically with passage of time after fire, or in other words, quality increases rapidly with new post-fire growth after a fire but then declines as the regrowth matures (Allred et al., 2011a). Mean stocking date was the 124th day (May 4th) and ranged from the 106th day (April 16th) to 140th day (May 20th). We define lag-time as the elapsed number of days after a fire is conducted and before cattle were stocked on a pasture. Lag-time has been proposed as an essential resource vari- 
a) Empirical data
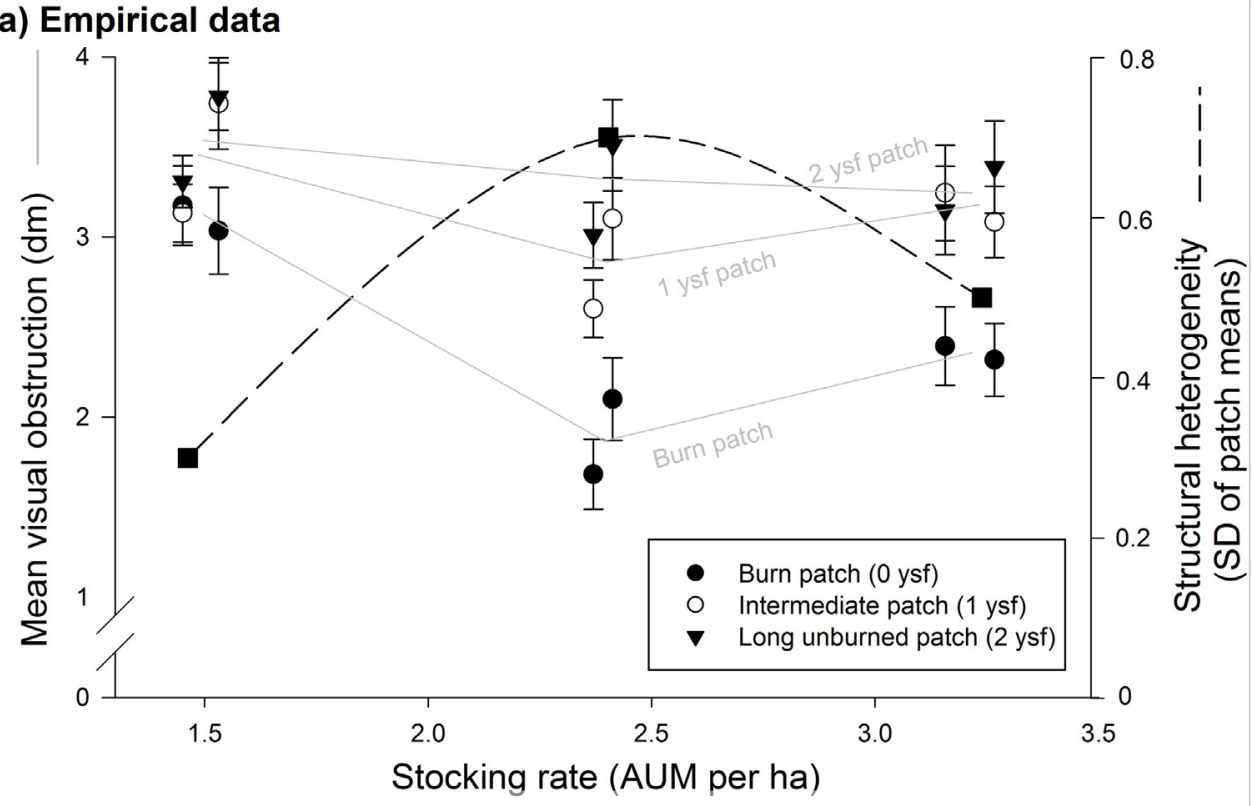

\section{b) Generalized model for grassland ecosystems}

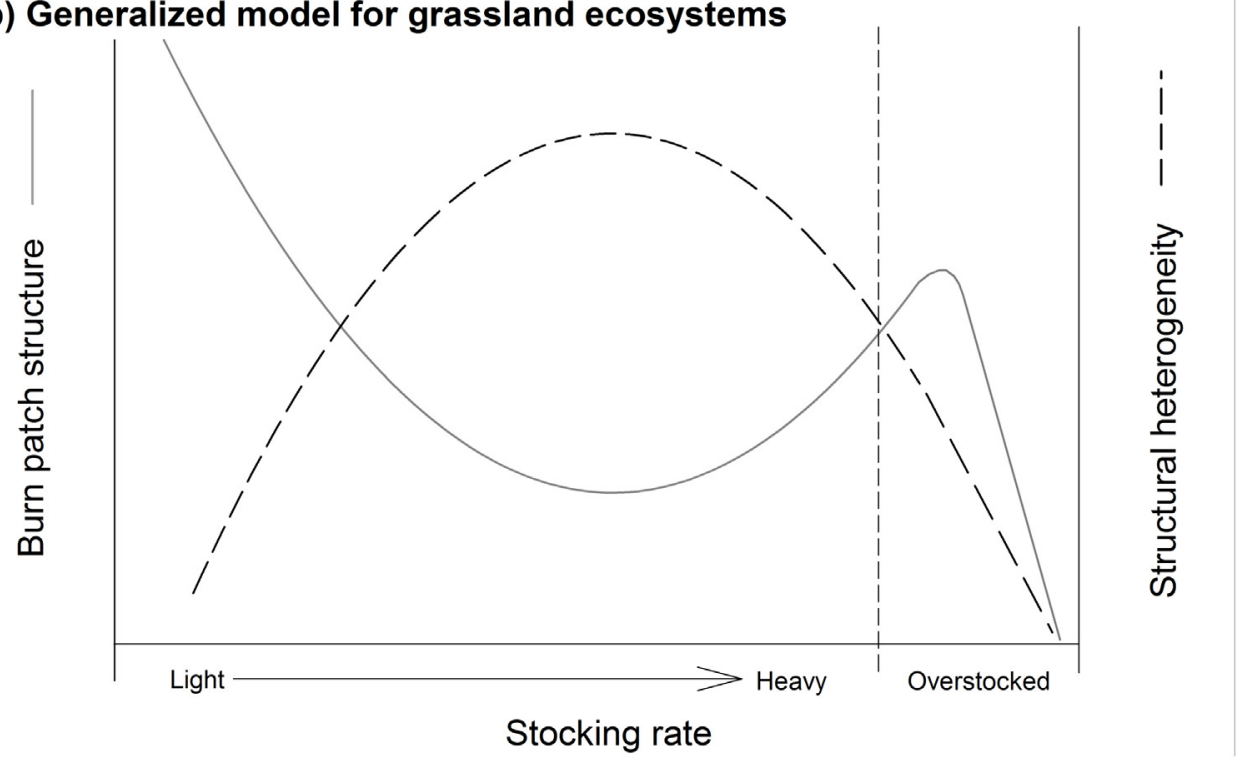

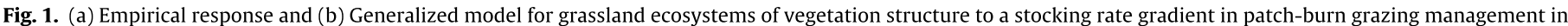

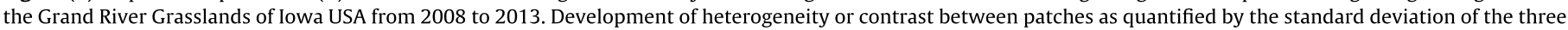

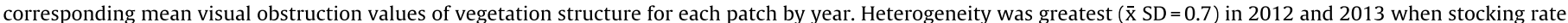
was moderate because low structure was established and maintained in the burn patch and structural heterogeneity or contrast between patches was maximized.

able for herbivore use of forage in fire-prone ecosystems because forage becomes less attractive as time-since fire increases, which inhibits attraction of cattle to a burned patch (Allred et al., 2011a; Klop et al., 2007).

Fire management was quantified with two variables: burn completeness and burn date. Both of these variables can be strongly affected by tall fescue abundance, live fuel moisture and plant phenology relative to green-up in the spring (McGranahan et al., 2012a; McGranahan et al., 2012b; McGranahan et al., 2013). We used burn completeness to measure prescribed fire efficacy, the proportion of the patch that was burned, which was a composite estimate by multiple observers immediately post-fire. If burns are incomplete, they may fail to achieve the homogenously low structure desired in the burn patch and the patchily burned areas may be less attractive to cattle, further interfering with the establishment of repetitive grazing and low vegetative structure. Mean burn day of the year was the 83rd day (March 24th) and ranged from the 65th day (March 6 th) to the 112th day (April 22nd).

Biotic features assessed included the cover of the vegetation: tall fescue, warm-season (C4) grass, and herbaceous litter. Tall fescue is important in this system because it is an invasive cool-season (C3) grass that can reduce fire spread, due to moisture content, and reduce herbivory, due to endophyte infection and alkaloid content, the two key features of the fire-grazing interaction (McGranahan et al., 2012a; McGranahan et al., 2012b; McGranahan et al., 2013). Warm-season grass cover and litter cover are a positive influence on fire potential because they provide the primary fuel for fire spread, and they are a negative influence on herbivory because of their low forage quality (Fuhlendorf and Engle, 2004; McGranahan et al., 2012b).

Topography, bare ground and precipitation are key abiotic features within the fire-grazing interaction. First, topography of a site, 
specifically slope, limits cattle distribution because foraging by cattle declines as slope increases (Allred et al., 2011a; Bailey et al., 1996; Vermeire et al., 2004). Secondly, amount of bare ground is an indicator of the degree of fuel discontinuity that restricts fire spread, or in other words discontinuity associated with bare ground creates fuel gaps (Knapp and Keeley, 2006); patches with large amounts of bare ground less effectively support fire spread, leading to patchy burned areas within the burned patch and a patch with less total fire-induced forage regrowth to attract cattle. Lastly, precipitation for the herbaceous biomass accumulation in the spring and summer can also influence fire and herbivory (Fay et al., 2000). Thus, we defined seasonal precipitation as the total accumulated precipitation from January 1 st to June 30th (henceforth precipitation) (Archibald et al., 2010; Smith, 1960). Mean seasonal precipitation was $582 \mathrm{~mm}$ and deviated $-130 \mathrm{~mm}$ (2012) to $+198 \mathrm{~mm}$ (2010) from the seven year mean.

\subsection{Modelling and analyses}

We used stocking rate, stocking date, lag-time, percent burn completeness, burn date, percent warm-season grass cover, percent herbaceous litter cover, percent tall fescue cover, precipitation, percent bare ground and slope as independent variables and burn patch visual obstruction as the dependent response variable. Stocking rate was relativized to a three-year mean of annual primary productivity for each pasture for analyses to account for intra-pasture variation (Scarnecchia and Kothmann, 1982). The three-year mean of annual primary productivity of each pasture was based on post-grazing forage residue samples taken in 2010 , 2011 and 2012 plus the amount of forage grazed during the grazing season based on animal demand. These three years included the wettest and driest years during the study. To meet assumptions of normality we log transformed stocking rate, burn completeness, litter, bare ground and precipitation.

We modeled cumulative effects on visual obstruction within burn patches and determined the top predictive models using Akaike's Information Criterion corrected for small sample sizes (AICc) using proc glimmix in SAS 9.3 (Burnham and Anderson, 2002; SAS Institute, 2011). The glimmix procedure allows the response variable to have a non-normal distribution, can account for nonlinear mixed models, and tests for random effects (SAS Institute, 2011). Modeling based on a priori identified explanatory variables allowed us to select the most parsimonious model (Burnham and Anderson, 2002). To account for variation through space and time, we used a mixed effects modeling approach and tested the potential random effects of Patch, Pasture, and Year. Patch, Pasture, and all possible combinations of Patch, Pasture, or Year did not improve the AICc, but Year singularly did and thus, was included as a random effect in all subsequent modeling steps (Null without Year as random AICC $=91.60$ and Null with Year as random AICC $=84.60$ ). At each step, AICc values were scaled relative to the top model (considered the model with the lowest AICc), thus the top model AICc was zero. Therefore, the best model at each step was based on $\triangle \mathrm{AICc}$ values $\leq 2$ (Burnham and Anderson, 2002). Difference between models ( $\triangle \mathrm{AICc}$ ) was calculated and used to rank models. Akaike weights $\left(\omega_{\mathrm{i}}\right)$ were calculated to assist in determining the top model as $\omega_{i}$ values indicate the relative likelihood of candidate models (Wagenmakers and Farrell, 2004). We first assessed a null model with no covariates. We then modeled four categories of variables separately: grazing, fire, biotic, abiotic factors. This approach allowed us to compare different metrics within each category, and subsequently to systematically build more complex models regardless of order. After we completed the categorical modeling steps, we used the top models from each category to assess models across all categories, again based on $\triangle \mathrm{AICC}$ values $\leq 2$ and also compared these to the null model and global model. We assessed Pearson correlation coefficients to ensure final candidate models did not include autocorrelated explanatory variables $(r>0.7)$ (Coppedge et al., 2008; Dzialak et al., 2013; Ribic and Sample, 2001). Finally, 95\% confidence intervals were calculated to further screen and identify uninformative parameters (Burnham and Anderson, 2002).

Based on the results of our modeling, we next sought to visually compare the top candidate models by graphing the mean visual obstruction of all patches based on stocking rate. Structural heterogeneity of the vegetation (i.e., the contrast between patches) was measured as the standard deviation between the mean visual obstruction of the most recently burned patch, the patch that had not been burned for over two years, and the intermediate patch burned the previous year following Fuhlendorf et al. (2006). Mean of burn completeness was graphed through time and considered in light of the top models. All analyses were conducted in SAS 9.2 (SAS Institute, 2011).

\section{Results}

Stocking rate, effective fires, and precipitation were the primary constraints to achieving low vegetative structure in the recently burned patch in our study. The single variable in the top model in the grazing modeling step was stocking rate; stocking date and lag-time models were not competitive (Table 4). Stocking rate was more influential for burn patch visual obstruction than stocking date or lag-time with $98 \%$ of the model weight based on Akaike weights $\left(\omega_{i}\right)$. The most influential variable in the top model in the fire modeling step was burn completeness; the burn-date model was not competitive (Table 4). Burn completeness was more influential for burn patch visual obstruction than burn date with $94 \%$ of the model weight.

Litter was the most influential variable in the top model in the biotic modeling step; warm-season grass and tall fescue were not competitive (Table 4). Litter was more influential for burn patch visual obstruction than warm-season grass or tall fescue with $91 \%$ of the model weight. Precipitation was the top model in the abiotic modeling step; bare ground and slope were not competitive (Table 4). Precipitation was more influential than bare ground or slope for burn patch visual obstruction with $83 \%$ of the model weight.

Two models were in the top set of combined grazing, fire, biotic, and abiotic predictive candidate models for burn patch visual obstruction (Table 4). Both included burn completeness, stocking rate and precipitation, and litter canopy cover was also an explanatory variable in the top model. The parameter estimate for stocking rate was positive, indicating that as the relative proportion of biomass allocated per animal unit increased (or stocking rate was reduced) burn patch visual obstruction increased. The parameter estimate for litter was also positive, indicating that litter canopy cover is correlated, or a result of, high burn patch visual obstruction. Parameter estimates for burn completeness and precipitation displayed an inverse relationship indicating that as the proportion of a patch that is burned increased and precipitation increased, burn patch visual obstruction decreased (Table 5). The 95\% confidence intervals of these four parameter estimates indicate that stocking rate, burn completeness and precipitation regulated burn patch visual obstruction establishment and maintenance, but litter canopy cover was not informative as its $95 \% \mathrm{CI}$ overlapped zero (Table 5; Burnham and Anderson, 2002). Thus, considering that the second-ranked model (without litter) has an AICc within 2 units of the top model (including litter), and considering 95\% CI's of litter, we conclude that burn completeness, stocking rate and precipitation were the most parsimonious and informative model predicting burn patch visual obstruction. 
Considering the phases of stocking rate adjustments relative to burn patch visual obstruction illustrates the mechanism driving the influence of grazing management. At the heaviest stocking rate ( $3.2 \pm 0.2 \mathrm{AUM} / \mathrm{ha})$, low vegetative structure in the burn patch may have been established but certainly was not maintained or different from the other patches (Fig. 1a). Furthermore, there was no separation between the intermediate patch and the patch not burned in over two years, potentially because although the heaviest stocking rate establishes low vegetative structure, cattle are forced to move into other patches to satisfy forage intake requirements. At the lightest stocking rate $(1.5 \pm 0.1 \mathrm{AUM} / \mathrm{ha})$, there was no establishment of low vegetative structure in the burn patch and very little separation between patches (Fig. 1a). However, at the moderate stocking rate $(2.4 \pm 0.2 \mathrm{AUM} / \mathrm{ha})$, the observed response more nearly matched the hypothetical response (Fig. 1a and Fig. 1b). Cattle both established and maintained low vegetative structure in the burned patch, and vegetative structure varied among the three patches. Percent utilization based on the three-year mean of total pasture forage based on the adjusted post-grazing forage residue measurements was $7 \%$ at the light stocking rate, $12 \%$ at the moderate stocking rate, and $16 \%$ at the heavy stocking rate (data not shown).

Heterogeneity of vegetative structure among patches was optimized at the moderate stocking rate. At the heaviest stocking rate the standard deviation was 0.5 , at the lightest stocking rate the standard deviation was 0.3 , and at the moderate stocking rate the standard deviation was 0.7. Thus, heterogeneity was $1.4-2.3$ times greater at the moderate stocking rate compared to the heavy or light stocking rates. The results in Fig. $1 \mathrm{a}$ indicate that the relationship between stocking rate and burn patch visual obstruction and vegetation structural heterogeneity is non-linear. Burn patch visual obstruction was lowest and heterogeneity was highest at intermediate levels of animal demand. In comparison, at lower and higher levels of animal demand, burn patch visual obstruction was higher and heterogeneity was lower than at intermediate levels. Based on these relationships, we propose a generalized model for grassland ecosystems for optimizing the interaction of stocking rate and fire in grassland systems to establish the desired vegetative structure for a diverse suite of wildlife species (Fig. 1b). Finally, when this experiment was initially established the completeness of prescribed fires was low due to light fuel loads and discontinuous fuel beds from heavy grazing which prevented effective spread of fires across patches (Fig. 2). However, through the course of this study, prescribed fire success improved with the increase of burn completeness (Fig. 2).

\section{Discussion}

In our study, the intermediate level of stocking of $2.4 \mathrm{AUM} / \mathrm{ha}$ resulted in the greatest levels of heterogeneity, however, the optimum stocking rate will likely vary across different ranges of net primary productivity (NPP) on different sites. For example, other North American fire-grazing interaction studies, across a broad precipitation gradient, reported stocking rates ranging from 0.5 AUM/ha to 4.3 AUM/ha (Allred et al., 2014; Augustine and Derner, 2014; Jamison and Underwood, 2008; McGranahan et al., 2012b; Smith, 2014). These studies have also had lower stocking rates when compared to other studies of seasonal continuous and rotational grazing systems in tallgrass prairie without fire ranging from 3.1 AUM/ha to 7.0 AUM/ha (Hickman et al., 2004; Towne et al., 2005). Based on utilization of the total pasture forage or the effective stocking rate in our study, cattle consumed $\sim 12 \%$ of the total forage. Conservative grazing recommendations without patchy fires have suggested using a $25 \%$ utilization level or $50 \%$ disappearance including trampling, decay, insect herbivory, etc.

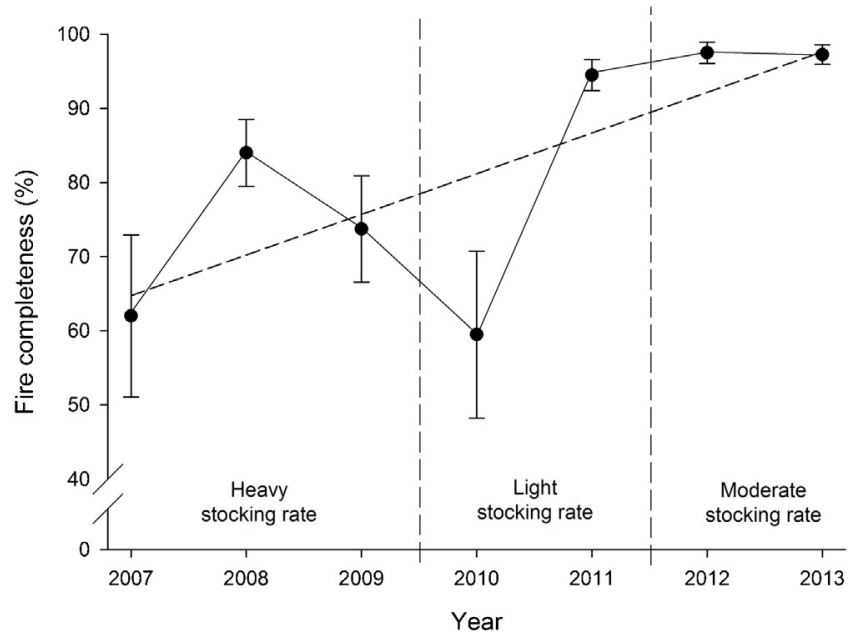

Fig. 2. Completeness of patch burns conducted in the Grand River Grasslands of Iowa USA from 2007 to 2013. Completeness is a visual estimate of $>2$ individuals. Percent of patch burned increased through time. Note the low completeness $\sim 60 \%$ in 2007 and 2010, years after the highest stocking rates (3.92 AUM/ha and 3.27 AUM/ha respectively) compared to high-level completeness 98\% in 2011 and 2013, years after low to moderate stocking rates (1.45 AUM/ha and $2.41 \mathrm{AUM} /$ ha respectively). Means and Standard Errors bars represent the mean of the four patches burned in four patch-burned pastures $(n=4)$

(Kothmann, 1984). This suggested lower rate in our study is justified because a single fire consumes about one-third of pasture biomass. A $50 \%$ reduction in stocking rate presents an economic tradeoff. Although total number of animals produced is reduced, restoring regular fire will sustain the forage base supporting the livestock enterprise by mitigating woody plant encroachment that reduces forage without fire in the long-term (Limb et al., 2010).

Our results indicate that large herbivores can physically engineer habitat, but efficacy is dependent on human management of stocking rates and burning as the primary engineers. Although the application of the fire-grazing interaction is fundamentally different than the utilitarian paradigm of more traditional rangeland management, basic stocking rate decisions remain fundamentally important (Briggs et al., 2002; Fuhlendorf et al., 2012). This insight addresses an essential knowledge gap (Fuhlendorf and Engle, 2004; Helzer and Steuter, 2005). Because grazing management decisions are controlled by the manager rather than biotic or abiotic features that often cannot be controlled, managers play the role of primary engineers of habitat structure, by altering grazing intensity. This information corresponds with the rangeland management principle that stocking rate is the key grazing management decision and more important than grazing system (Briske et al., 2011; Hickman et al., 2004; Holechek et al., 2001). For these reasons, determining the effective stocking rate is essential for the successful application of patch-burning on fragmented landscapes and for realizing benefits to biodiversity (Coppedge et al., 2008; Davit, 2008; Duchardt et al., 2016; Fuhlendorf et al., 2006). This is also related to the ability to successfully conduct prescribed fires. For example, heavy stocking rates in 2007, 2008, and 2009 may explain, at least in part, the limited ability to conduct complete prescribed fires and the cause of limited fire spread. This result was driven by cattle selecting all patches rather than preferentially grazing the recently burned patch. However, focal grazing in the burn patch was optimized at intermediate stocking rates which enhanced fuel accumulation and continuity in the long-unburned patch (Kerby et al., 2007).

Our results confirm the inverse relationship between stocking rate and ineffective prescribed fires. This result is explained by the phenomenon when heavy grazing commonly creates fuel discontinuity that disrupts fire spread (Davies et al., 2010; Derner and 


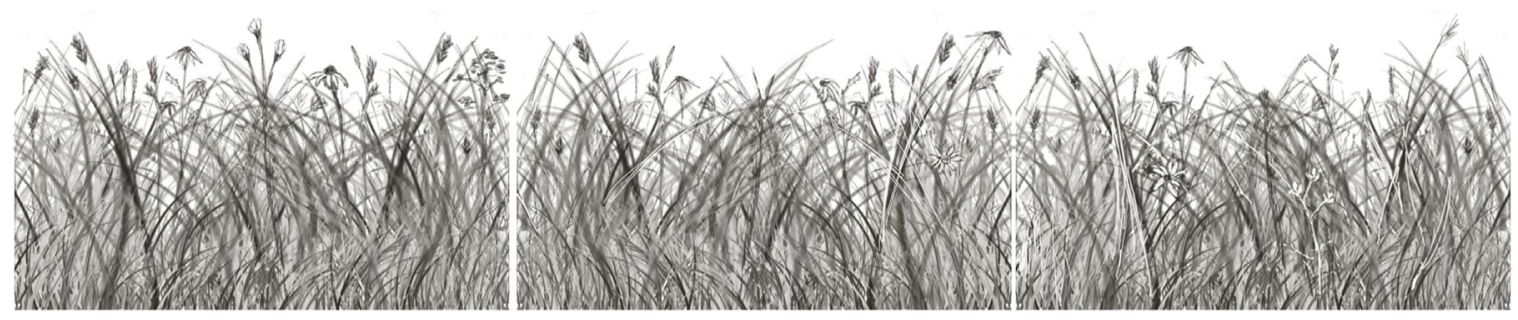

b)

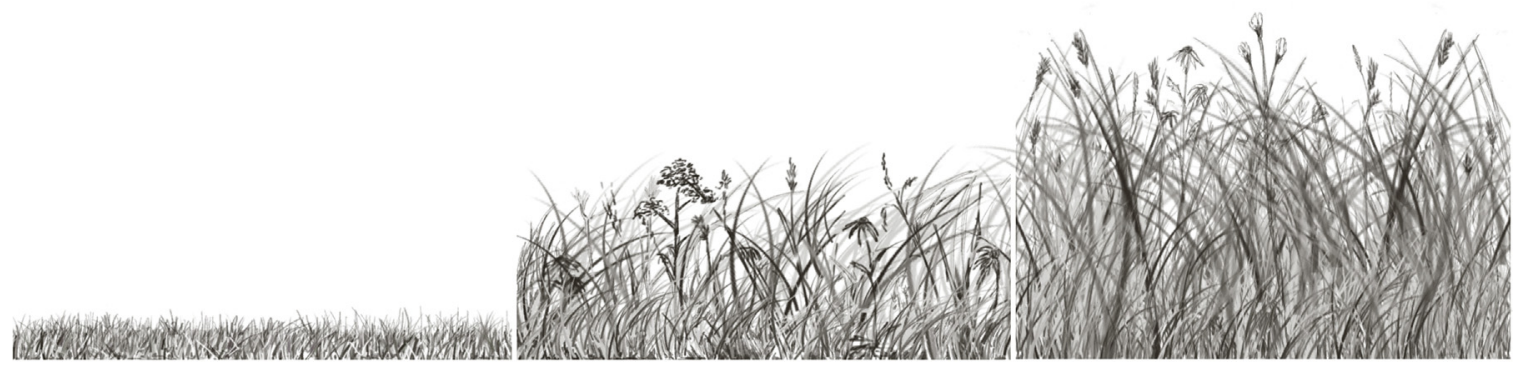

c)

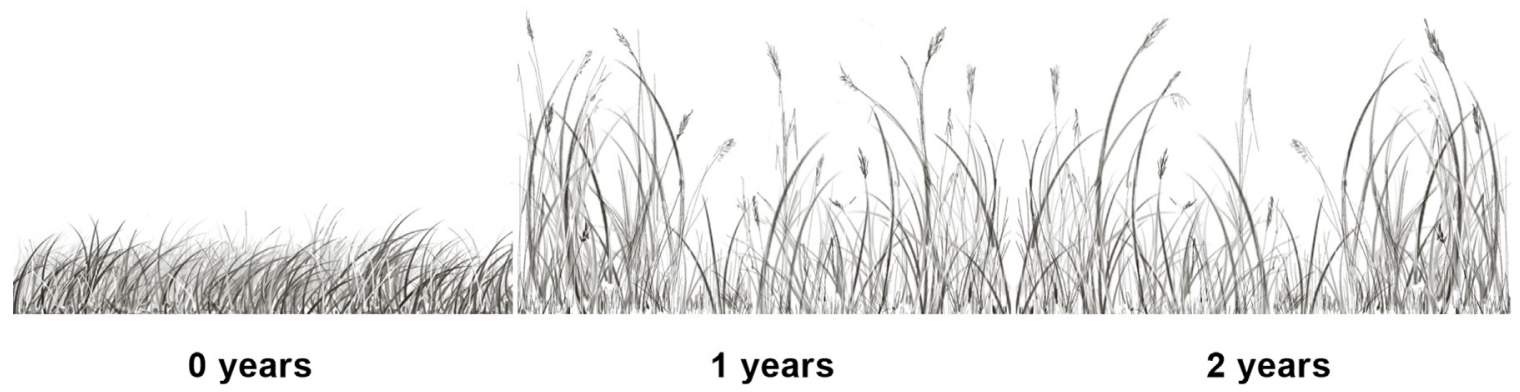

Patch elapsed time since fire

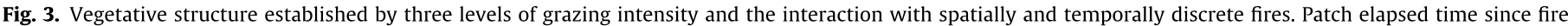

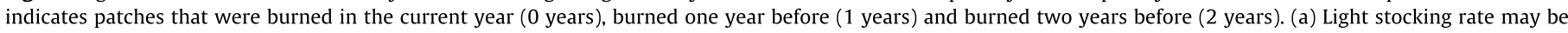

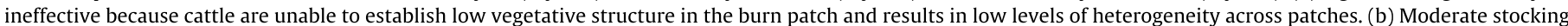

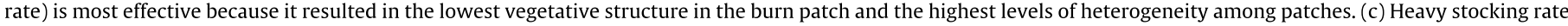

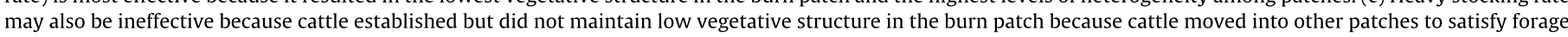
intake requirements. Consequently, cattle modify fuel continuity, fuel load and fire behavior in unburned patches making it difficult to conduct complete prescribed fires.

Whitman, 2009; Leonard et al., 2010). However, once stocking rate was moderated in 2010, burn completeness improved, albeit with a one-year lag period (Fig. 2). Reduced stocking rate in 2010 also may have had a rest or deferment effect and been necessary to reinstate effective prescribed fires after heavy stocking in the earlier years (McGranahan et al., 2012b). In other words, reduced stocking rate allowed additional fuel to accumulate, which bridged fuel gaps. Establishing fire-driven grazing patterns can also improve the ability to burn after drought years. Evidence of this in our study is that the most complete burns during our study were achieved in 2013 , the year after the lowest year of precipitation in our study.
This indicates that moderate grazing in this system can override inter-annual variation of precipitation.

However, stocking rates are difficult to interpret and compare in the context of variable annual primary productivity across pastures and regions. For example, in the first phase of research at our study location, stocking rate (3.1 AUM/ha) in 2007-2010 was considered 'heavy' compared to four other studies in other regions (0.8-4.3 AUM/ha noted to vary from light to moderate) (McGranahan et al., 2012b). However, when stocking rate is relativized to annual primary productivity for the five locations, the stocking rate was the lightest at our study location during that time period (McGranahan et al., 2012b). Furthermore, our study sites 
had a history of abusively heavy stocking and were highly invaded by $\mathrm{C} 3$ exotic plants, so responses may not be comparable to C4dominated prairies because of asynchronous growing and burning patterns or early green-up of $\mathrm{C} 3$ plants prior to the early spring burn season (McGranahan et al., 2012a; Ode et al., 1980).

Based on our data and the non-linear relationship between stocking rate and burn patch visual obstruction and heterogeneity, we propose a generalized model for grassland ecosystems to guide grazing decisions within fire-driven management schemes. In this model, the appropriately applied intermediate stocking rate is essential for establishing and maintaining low vegetative structure in the burn patch and optimizing heterogeneity (Fig. 1b). This generalized model is based on the relationship between stocking rate, burn patch vegetative structure and heterogeneity, a relationship that is non-linear. Intermediate stocking rate minimizes the low structure by establishing and maintaining low vegetative structure in the burn patch and maximize the structural heterogeneity or contrast between patches. When stocking rates are too light, cattle cannot establish low vegetative structure in the burn patch, and when stocking rates are too heavy cattle cannot maintain low vegetative structure in the burn patch.

The inverse relationship of precipitation with vegetative structure (as measured by visual obstruction) indicates precipitation is needed to maintain low vegetative structure - a relationship that intuitively seems paradoxical. However, if precipitation is low, early vegetative growth slows or stops and animals leave the patch to satisfy forage intake requirements. Some minimal amount of precipitation is required to engineer a contrast among patches, yet, if there was too much precipitation the relationship would not hold as plant growth would overwhelm downward herbivore pressure in the patch and reduce strength of attraction to the burn patch. The importance to our overall top model corresponds with research from mixed grass prairie suggestion precipitation and stocking rate explains proportional relative variation of peak standing crop (Derner and Hart, 2007). Furthermore, precipitation pulses, not only annual precipitation, in semi-arid rangeland are an influential control of the strength and timing of fire-grazer interactions (Augustine and Derner, 2014). Timing of precipitation, according to our results, is an important influence on the strength of the fire-grazing interaction in our study.

Our research demonstrates that the careful application of grazing and fire can be an effective way to manipulate plant succession and structure in grasslands. This is important when managing for wildlife habitat in working landscapes (Derner et al., 2009; Fuhlendorf et al., 2006; Miller et al., 2012; Quan et al., 2015). In fragmented landscapes where exotic plant species invasion is prevalent, constraints to using patchy fires to manipulate cattle grazing distribution, and thus vegetation structure, included stocking rate, date of burn completion and precipitation. Our initial hypothesis that the exotic C3 grass tall fescue, lag-time between burning and stocking cattle, and burn date would be the primary constraining factors was not supported by the results of our study. Using patchy fires to manipulate grazing distribution at this location was ineffective in the early years of the study, presumably because of the exotic C3 graminoid tall fescue and overgrazing that occurred before the start of the experiment (McGranahan et al., 2012a). However, tall fescue abundance was not correlated with burn completeness $(r=0.09, P=0.62)$ and did not apparently constrain burn efficacy.

Tall fescue maintains a defensive mutualism with a fungal endophyte which deters grazers, much like tannins in Lespedeza cuneata (Clay, 1988; Cummings et al., 2007). L. cuneata has been found to be affected by application of fire and grazing, and our results indicate that the fire-grazing interaction can also override the herbivory constraints of tall fescue that is infected by the fungal endophyte. Because focal grazing in the burn patch should maintain younger stages of plant growth for longer periods of time (Allred et al., 2011a), fungal endophyte development on an individual plant is likewise impeded (Hall et al., 2014; Rottinghaus et al., 1991). The fire-grazing interaction can also override the high moisture content and altered fuelbed characteristics associated with tall fescue invasion that inhibits fire spread (Kerby et al., 2007; McGranahan et al., 2012a; McGranahan et al., 2013).

Optimizing stocking rate allows managers to successfully establish vegetative structural heterogeneity with the ecological interaction of fire and grazing and potentially reversing homogenization of grassland habitat and declines of grassland bird populations (Brennan and Kuvlesky Jr., 2005; Fuhlendorf et al., 2006). At too light of stocking rates, no burn patch is established and the vegetative structure is high and primarily suitable only for grassland birds that need high vegetative structure and litter such as Henslow's sparrows (Ammodramus henslowii) or generalists such as bobolinks (Dolichonyx oryzivorus) (Hovick et al., 2015) (Fig. 3a). We hypothesize this effect is due to the few number of cattle were unable to adequately consume post-fire vegetative regrowth in the burn patch. The primary function driving cattle-induced modifications to habitat require focusing grazing in a patch within a larger pasture which is optimized at intermediate stocking rates because the burn patch is established and maintained and biomass accumulation is maximized in the long-unburned patch (Fig. 3b). This modification of habitat structure to establish low structure in the burn patch could benefit mountain plovers (Charadrius montanus) and Smith's longspur (Calcarius pictus) in other systems (Derner et al., 2009). The structural heterogeneity across patches would be of value to upland sandpipers (Bartramia longicauda), long-billed curlews (Numenius americanus), and lesser prairie chickens (Tympanuchus pallidicinctus) that require both low and high vegetation structure (Derner et al., 2009; Hovick et al., 2015). At heavy stocking rates, the burn patch is established but not maintained and as cattle move to other patches to satisfy intake requirements, biomass accumulation is reduced and fuel continuity is negatively altered (Fig. 3c). Finally, we had higher obligate grassland bird species diversity at our research location when moderate stocking rates were employed compared to burning and grazing entire pastures, not burning at all and grazing, or burning entire pastures without grazing (Duchardt et al., 2016). These bird responses are attributed to the restoration of landscape fire and grazing interactive processes to engineer grassland habitat structure and manipulate plant succession as an ecological engineering tool (Byers et al., 2006; Jing et al., 2014; Kangas, 2004; Meira-Neto et al., 2011). This supports the concept that engineering habitat recovery and ecosystem function should begin by restoring or changing the interaction of biotic-abiotic processes and we suggest restoring how fire and grazing interact can be optimized with the stocking rate decision in invaded and fragmented prairies (Byers et al., 2006; Kangas, 2004).

Thus, managing rangeland with interactive fire and grazing can sustain cattle production while optimizing wildlife habitat (Allred et al., 2014; Fuhlendorf et al., 2006; Limb et al., 2011; Polito et al., 2013; Scasta et al., 2012; Scasta et al., 2015). While our results suggest that grazing utilization should be lower than typical utilization rates without fire, the positive benefit of restoring fire and grazing interactive processes should prevent transition from grassland to a juniper woodland state and will ensure the ability to graze in the long term (Engle et al., 1987; Limb et al., 2010). Even though this approach to managing rangelands is novel and integrates conservation and production goals, basic rangeland management principles such as stocking rate still apply (Fuhlendorf et al., 2012).

The fire-grazing interaction, applied as patch-burn grazing, has not been proposed as an ecological engineering approach for grassland habitat structure, but we suggest that restoration of these developmental disturbances to maintain grasslands correlates with the imitation principle of ecological engineering (Jǿrgensen and 
Nielsen, 1996; Lü et al., 2011). Our study also indicates that prior overgrazing, exotic species and other biotic and abiotic features may impede the interaction of fire and grazing, but the efficacy of restoring fire-grazing processes and vegetation structural patterns is still regulated by fire, grazing and climate (Anderson, 2006). Furthermore, stocking rate continues to be the key grazing management decision that is more important than the grazing system, even fire-driven grazing systems and corresponds to the efficacy of prescribed fires (Briske et al., 2011; Holechek et al., 2001). This paradigm also mimics ancient human management practices of using fire to manipulate animal movements and vegetation and restores an ecosystem engineer proxy that modifies grassland habitat via the biotic-abiotic interaction with fire (Jones et al., 1996; Kangas, 2004). Finally, while the term 'ecosystem engineer' has been applied to individual species to describe their role in modifying the ecosystem, the effective application of grazing with fire to structure grassland habitat features is dependent upon the manager's decision of stocking rate as the essential component that dictates success of the fire-grazing interaction.

\section{Acknowledgements}

Research was funded by the Iowa Department of Natural Resources, Iowa Agricultural and Home Economics Experiment Station, and the Iowa State Wildlife Grants program grant \#-U-2-R-1 in cooperation with the U.S. Fish and Wildlife Service, Wildlife and Sport Fish Restoration Program (\#-U-2-R-1) and supported in part by the University of Wyoming Department of Ecosystem Science and College of Agriculture and Natural Resources. We also recognize the original artwork of Vince Gianotti, Oklahoma State University Ag Communications Services.

\section{Appendix A. Supplementary data}

Supplementary data associated with this article can be found, in the online version, at http://dx.doi.org/10.1016/j.ecoleng.2016.06. 096.

\section{References}

Allred, B.W., Fuhlendorf, S.D., Engle, D.M., Elmore, R.D., 2011a. Ungulate preference for burned patches reveals strength of fire-grazing interaction. Ecol. Evol. 1 $132-144$.

Allred, B.W., Fuhlendorf, S.D., Hamilton, R.G., 2011b. The role of herbivores in Great Plains conservation: comparative ecology of bison and cattle. Ecosphere 2, $1-17$.

Allred, B.W., Scasta, J.D., Hovick, T.J., Fuhlendorf, S.D., Hamilton, R.G., 2014. Spatial heterogeneity stabilizes livestock productivity in a changing climate. Agric. Ecosyst. Environ. 193, 37-41.

Anderson, R.C., 2006. Evolution and origin of the central grassland of North America: climate fire, and mammalian grazers. J. Torrey Bot. Soc. 133, 626-647.

Archibald, S., Bond, W.J., Stock, W.D., Fairbanks, D.H.K., 2005. Shaping the landscape: fire-grazer interactions in an African savanna. Ecol. Appl. 15 96-109.

Archibald, S., Scholes, R.J., Roy, D.P., Roberts, G., Boschetti, L., 2010. Southern African fire regimes as revealed by remote sensing. Int. J. Wildland Fire. 19 $861-878$.

Augustine, D.J., Derner, J.D., 2014. Controls over the strength and timing of fire-grazer interactions in a semi-arid rangeland. J. Appl. Ecol. 51, 242-250.

Bailey, D.W., Gross, J.E., Laca, E.A., Rittenhouse, L.R., Coughenour, M.B., Swift, D.M., Sims, P.L., 1996. Mechanisms that result in large herbivore grazing distribution patterns. J. Range Manag. 49, 386-400.

Brennan, L.A., Kuvlesky Jr., W.P., 2005. Invited paper: North American grassland birds: an unfolding conservation crisis? J. Wildl. Manag. 69, 1-13.

Briggs, J.M., Knapp, A.K., Brock, B.L., 2002. Expansion of woody plants in tallgrass prairie: a fifteen-year study of fire and fire-grazing interactions. Am. Midl. Nat. $147,287-294$

Briske, D.D., Derner, J.D., Milchunas, D.G., Tate, K.W., 2011. An evidence-based assessment of prescribed grazing practices. In: Conservation Benefits of Rangeland Practices: Assessment, Recommendations, and Knowledge Gaps. Natural Resources Conservation Service, US Department of Agriculture.

Burnham, K.P., Anderson, D.R., 2002. Model Selection and Multi-model Inference A Practical Information-theoretic Approach. Springer, New York, USA.
Byers, J.E., Cuddlington, K., Jones, C.G., Talley, T.S., Hastings, A., Lambrinos, J.G., Crooks, J.A., Wilson, W.G., 2006. Using ecosystem engineers to restore ecological systems. Trends Ecol. Evol. 21, 493-500.

Chapman, S.S., Omernik, J.M., Griffith, G.E., Schroeder, W.A., Nigh, T.A., Wilton, T.F., 2002. Ecoregions of Iowa and Missouri. U.S. Geological Survey, Reston, Virginia, USA.

Clay, K., 1988. Fungal endophytes of grasses: a defensive mutualism between plants and fungi. Ecology 69, 10-16.

Coppedge, B.R., Fuhlendorf, S.D., Harrell, W.C., Engle, D.M., 2008. Avian community response to vegetation and structural features in grasslands managed with fire and grazing. Biol. Conserv. 141, 1196-1203.

Cummings, D.C., Fuhlendorf, S.D., Engle, D.M., 2007. Is altering grazing selectivity of invasive forage species with patch burning more effective than herbicide treatments? Rangel. Ecol. Manag. 60, 253-260.

Daubenmire, R., 1959. A canopy-coverage method of vegetational analysis. Northwest Sci. 33, 43-64.

Davies, K.W., Bates, J.D., Svejcar, T.J., Boyd, C.S., 2010. Effects of long-term livestock grazing on fuel characteristics in rangelands: an example from the sagebrush steppe. Rangel. Ecol. Manag. 63, 662-669.

Davit, C., 2008. Grand river grasslands conservation opportunity area (COA). Mo. Prairie J. 29, 11-12.

Derner, J.D., Hart, R.H., 2007. Grazing-induced modifications to peak standing crop in northern mixed-grass prairie. Rangel. Ecol. Manag. 60, 270-276.

Derner, J.D., Whitman, A.J., 2009. Plant interspaces resulting from contrasting grazing management in northern mixed-grass prairie: implications for ecosystem function. Rangel. Ecol. Manag. 62, 83-88.

Derner, J.D., Lauenroth, W.K., Stapp, P., Augustine, D.J., 2009. Livestock as ecosystem engineers for grassland bird habitat in the western Great Plains of North America. Rangel. Ecol. Manag. 62, 111-118.

Duchardt, C.J., Miller, J.R., Debinski, D.M., Engle, D.M., 2016. Adapting the fire-grazing interaction to small pastures in a fragmented landscape for grassland bird conservation. Rangel. Ecol. Manag., http://dx.doi.org/10.1016/j. rama.2016.03.005, in press.

Dzialak, M.R., Webb, S.L., Harju, S.M., Olson, C.V., Winstead, J.B., Hayden-Wing, L.D. 2013. Greater sage-grouse and severe winter conditions: identifying habitat for conservation. Rangel. Ecol. Manag. 66, 10-18

ESRI, 2011. ArcGIS Desktop: Release 10. Environmental Systems Research Institute, Redlands, CA, USA.

Engle, D.M., Stritzke, J.F., Claypool, P.L., 1987. Herbage standing crop around eastern redcedar trees. Rangel. Ecol. Manag. 40, 237-239.

Fay, P.A., Carlisle, J.D., Knapp, A.K., Blair, J.M., Collins, S.L., 2000. Altering rainfall timing and quantity in a mesic grassland ecosystem: design and performance of rainfall manipulation shelters. Ecosystems 3, 308-319.

Fuhlendorf, S.D., Engle, D.M., 2001. Restoring heterogeneity on rangelands: ecosystem management based on evolutionary grazing patterns. Bioscience 51, 625-632.

Fuhlendorf, S.D., Engle, D.M., 2004. Application of the fire-grazing interaction to restore a shifting mosaic on tallgrass prairie. J. Appl. Ecol. 41, 604-614.

Fuhlendorf, S.D., Harrell, W.C., Engle, D.M., Hamilton, R.G., Davis, C.A., Leslie Jr., D.M., 2006. Should heterogeneity be the basis for conservation? Grassland bird response to fire and grazing. Ecol. Appl. 16, 1706-1716.

Fuhlendorf, S.D., Engle, D.M., Kerby, J., Hamilton, R.G., 2009. Pyric herbivory: rewilding landscapes through the recoupling of fire and grazing. Conserv. Biol. 23, 588-598.

Fuhlendorf, S.D., Engle, D.M., Elmore, R.D., Limb, R.F., Bidwell, T.G., 2012. Conservation of pattern and process: developing an alternative paradigm of rangeland management. Rangel. Ecol. Manag. 65, 579-589.

Hall, S.L., McCulley, R.L., Barney, R.J., Phillips, T.D., 2014. Does fungal endophyte infection improve tall fescue's growth response to fire and water limitation? PLoS One 9, e86904, http://dx.doi.org/10.1371/journal.pone.0086904.

Helzer, C.J., Steuter, A.A., 2005. Preliminary effects of patch-burn grazing on a high-diversity prairie restoration. Ecol. Restor. 23, 167-171.

Hickman, K.R., Hartnett, D.C., Cochran, R.C., Owensby, C.E., 2004. Grazing management effects on plant species diversity in tallgrass prairie. Rangel. Ecol. Manag. 57, 58-65.

Holechek, J.L., Pieper, R.D., Herbel, C.H., 2001. Range Management: Principles and Practices, 4th ed. Prentice-Hall, New Jersey, USA

Hovick, T.J., Elmore, R.D., Fuhlendorf, S.D., Engle, D.M., Hamilton, R.G., 2015. Spatial heterogeneity increases diversity and stability in grassland bird communities. Ecol. Appl. 25, 662-672.

Iowa Environmental Mesonet, 2014. IEM Climodat for Mt. Ayr, Iowa Mesonet Station, http://mesonet.agron.iastate.edu/climodat/ (accessed 26.2.16).

Iowa NRGIS, 2013. Iowa Natural Resources Geographic Information Systems Library. Department of Natural Resrouces, http://www.igsb.uiowa.edu/ nrgislibx/ (accessed 26.2.).

Jǿrgensen, S.E., Nielsen, S.N., 1996. Application of ecological engineering principles in agriculture. Ecol. Eng. 7, 373-381.

Jamison, B., Underwood, M., 2008. Evaluation of a grazing system for maintaining grassland integrity and improving upland bird habitat. In: Missouri Department of Conservation Final Project Report, http://www.nrcs.usda.gov/ Internet/FSE_DOCUMENTS/stelprdb1044913.pdf (accessed 26.2.16).

Jing, Z., Cheng, J., Su, J., Bai, Y., Jin, J., 2014. Changes in plant community composition and soil properties under 3-decade grazing exclusion in semiarid grassland. Ecol. Eng. 64, 171-178.

Jones, C.G., Lawton, J.H., Shachak, M., 1996. Organisms as ecosystem engineers. In: Ecosystem Management. Springer, New York, USA. 
Kangas, P.C., 2004. Ecological Engineering: Principles and Practice. CRC Press, Boca Raton, USA.

Kerby, J.D., Fuhlendorf, S.D., Engle, D.M., 2007. Landscape heterogeneity and fire behavior: scale-dependent feedback between fire and grazing processes. Landsc. Ecol. 22, 507-516.

Klop, E., van Goethem, J., de Longh, H.H., 2007. Resource selection by grazing herbivores on post-fire regrowth in a West African woodland savanna. Wildl. Res. 34, 77-83.

Knapp, E.E., Keeley, J.E., 2006. Heterogeneity in fire severity within early season and late season prescribed burns in a mixed-conifer forest. Int. J. Wildland Fire $15,37-45$.

Kothmann, M.M., 1984. Concepts and principles underlying grazing systems. In: In: NRC/NAS. Developing Strategies for Rangeland Management. Westview Press, Boulder, CO, USA.

Lü, X.T., Cui, Q., Wang, Q.B., Han, X.G., 2011. Nutrient resorption response to fire and nitrogen addition in a semi-arid grassland. Ecol. Eng. 37, 534-538.

Leis, S.A., Morrison, L.W., Debacker, M.D., 2013. Spatiotemporal variation in vegetation structure resulting from pyric-herbivory. Prairie Nat. 45, 13-20.

Leonard, S., Kirkpatrick, J., Marsden-Smedley, J., 2010. Variation in the effects of vertebrate grazing on fire potential between grassland structural types. J. Appl. Ecol. 47, 876-883.

Levin, S.A., 1992. The problem of pattern and scale in ecology: the Robert $H$. MacArthur award lecture. Ecology 73, 1943-1967.

Limb, R.F., Engle, D.M., Alford, A.L., Hellgren, E.C., 2010. Tallgrass prairie plant community dynamics along a canopy cover gradient of eastern redcedar (Juniperus virginiana L.). Rangel. Ecol. Manag. 63, 638-644.

Limb, R.F., Fuhlendorf, S.D., Engle, D.M., Weir, J.R., Elmore, R.D., Bidwell, T.G., 2011 Pyric-herbivory and cattle performance in grassland ecosystems. Rangel. Ecol. Manag. 64, 659-663.

Machicote, M., Branch, L.C., Villarreal, D., 2004. Burrowing owls and burrowing mammals: are ecosystem engineers interchangeable as facilitators? Oikos 106, 527-535.

McGranahan, D.A., Engle, D.M., Fuhlendorf, S.D., Miller, J.R., Debinski, D.M., 2012a. An invasive cool-season grass complicates prescribed fire management in a native warm-season grassland. Nat. Areas J. 32, 208-214.

McGranahan, D.A., Engle, D.M., Fuhlendorf, S.D., Winter, S.J., Miller, J.R., Debinski, D.M., 2012b. Spatial heterogeneity across five rangelands managed with pyric-herbivory. J. Appl. Ecol. 49, 903-910.

McGranahan, D.A., Engle, D.M., Miller, J.R., Debinski, D.M., 2013. An invasive grass increases live fuel proportion and reduces fire spread in a simulated grassland. Ecosystems 16, 158-169.

Meira-Neto, J.A.A., Clemente, A., Oliveira, G., Nunes, A., Correia, O., 2011. Post-fire and post-quarry rehabilitation successions in Mediterranean-like ecosystems: implications for ecological restoration. Ecol. Eng. 37, 1132-1139.

Miller, J.R., Morton, L.W., Engle, D.M., Debinski, D.M., Harr, R.N., 2012. Nature reserves as catalysts for landscape change. Front. Ecol. Environ. 10, 144-152.
Ode, D.J., Tieszen, L.L., Lerman, J.C., 1980. The seasonal contribution of C3 and C4 plant species to primary production in a mixed prairie. Ecology 61, 1304-1311. Polito, V.J., Baum, K.A., Payton, M.E., Little, S.E., Fuhlendorf, S.D., Reichard, M.V., 2013. Tick abundance and levels of infestation on cattle in response to patch burning. Rangel. Ecol. Manag. 66, 545-552.

Quan, Q., Nianpeng, H., Zhen, Z., Yunhai, Z., Yang, G., 2015. Nitrogen enrichment and grazing accelerate vegetation restoration in degraded grassland patches. Ecol. Eng. 75, 172-177.

Ribic, C.A., Sample, D.W., 2001. Associations of grassland birds with landscape factors in southern Wisconsin. Am. Midl. Nat. 146, 105-121.

Robel, R.J., Briggs, J.N., Dayton, A.D., Hulbert, L.C., 1970. Relationships between visual obstruction measurements and weight of grassland vegetation. J. Range Manag. 23, 295-297.

Rottinghaus, G.E., Garner, G.B., Cornell, C.N., Ellis, J.L., 1991. HPLC method for quantitating ergovaline in endophyte-infested tall fescue: seasonal variation of ergovaline levels in stems with leaf sheaths leaf blades, and seed heads. J Agric. Food. Chem. 39, 112-115

S.A.S. Institute, 2011. SAS 9.2 User's Guide Cary, NC, USA.

Scarnecchia, D.L., Kothmann, M.M., 1982. A dynamic approach to grazing management terminology. J. Range Manag. 35, 262-264.

Scasta, J.D., Engle, D.M., Talley, J.L., Weir, J.R., Stansberry, J.C., Fuhlendorf, S.D., Harr R.N., 2012. Pyric-herbivory to manage horn flies (Diptera: Muscidae) on cattle. Southwest. Entomol. 37, 325-334.

Scasta, J.D., Engle, D.M., Harr, R.N., Debinski, D.M., 2014. Fire induced reproductive mechanisms of a Symphoricarpos (Caprifoliaceae) shrub after dormant season burning. Bot. Stud. 55, 80.

Scasta, J.D., Thacker, E.T., Hovick, T.J., Engle, D.M., Allred, B.W., Fuhlendorf, S.D. Weir, J.R., 2015. Patch-burn grazing (PBG) as a livestock management alternative for fire-prone ecosystems of North America. Renew. Agric. Food Syst., 1-18, http://dx.doi.org/10.1017/s1742170515000411, First View.

Smith, E.L., 1960. Effects of burning and clipping at various times during the wet season on tropical tall grass range in northern Australia. J. Range Manag. 13, 197-203.

Smith, B.W., 2014. Vegetation Pattern and Response in the Context of Heterogeneous Pasture Management in Southeastern Nebraska. Thesis. Oklahoma State University, Stillwater, OK, USA, 77p.

Towne, E.G., Hartnett, D.C., Cochran, R.C., 2005. Vegetation trends in tallgrass prairie from bison and cattle grazing. Ecol. Appl. 15, 1550-1559.

Turner, M.G., 1989. Landscape ecology: the effect of pattern on process. Annu. Rev. Ecol. Syst. 20, 171-197.

Vermeire, L.T., Gillen, R.L., 2001. Estimating herbage standing crop with visual obstruction in tallgrass prairie. J. Range Manag. 54, 57-60.

Vermeire, L.T., Mitchell, R.B., Fuhlendorf, S.D., Gillen, R.L., 2004. Patch burning effects on grazing distribution. Rangel. Ecol. Manag. 57, 248-252.

Wagenmakers, E.J., Farrell, S., 2004. AIC model selection using Akaike weights. Psychon. B Rev. 11, 192-196. 